\title{
Can Learning about History of Science and Nature of Science in a Student-Centred Classroom Change Science Students' Conception of Science?
}

\author{
Fereshte Heidari Khazaei, Baptiste Roucau, Calvin S. Kalman \\ Concordia University, Montreal, Canada \\ Email: Calvin.Kalman@concordia.ca
}

How to cite this paper: Khazaei, F. H., Roucau, B., \& Kalman, C. S. (2018). Can Learning about History of Science and Nature of Science in a Student-Centred Classroom Change Science Students' Conception of Science? Creative Education, 9, 2561-2591.

https://doi.org/10.4236/ce.2018.915194

Received: October 4, 2018

Accepted: November 19, 2018

Published: November 22, 2018

Copyright $(9) 2018$ by authors and Scientific Research Publishing Inc. This work is licensed under the Creative Commons Attribution International License (CC BY 4.0).

http://creativecommons.org/licenses/by/4.0/

\section{(c) (i) Open Access}

\begin{abstract}
Nature of Science (NOS) covers the aim, development, criticism and explanation of science. This study examines the impact that studying philosophy and history of science has on undergraduate students' views about the NOS. Studying the NOS helps students to understand what science is, how to characterize the nature of its practitioners' activities, and what is the significance of the whole enterprise. It is shown that having students study scientific concepts through the eyes of philosophers and historical scientists, actively engages them in the process of inquiry and challenges them to increase their understanding of the NOS. This study showed that studying philosophy and history of science in a student-centered classroom had a strong influence on students' views about the NOS in that many students changed their views about the NOS. Students who did not change their over-all perception gave much clearer expositions of their views.
\end{abstract}

\section{Keywords}

Nature of Science, History of Science, Philosophy of Science,

Reflective Writing, Course Dossier

\section{Introduction}

The importance of accurately and deliberately teaching the Nature of Science (NOS) when teaching science to students is widely recognized (Clough \& Olson, 2008), see also Duschl (2000), Supovitz \& Turner (2000) and Parkinson (2004). We can also say a main goal of science education is to create scientific literacy 
and a scientific literate person needs a deep understanding about the NOS (Akcay \& Ackay, 2015). Akcay also states that understanding the NOS is a critical objective and to achieve this understanding, students need to learn about the processes through which science develops. Further support to report the effectiveness of interventions related to the NOS is shown in these two studies.

One study that investigated teaching experiences applying History and Philosophy of Science (HPS) in a physics classroom, with the aim of obtaining critical and reliable information on this subject was done by de Carvalho and Vannucchi (2000) in Germany. This study involves qualitative research with a group of secondary school students on the historical development of optics, especially events involving Galileo using a telescope. Group activities took place in a classroom with questions proposed and mediated by the teacher. After reading and analyzing historical texts, there were activities in which students discussed the subject with a view to better understanding essential aspects of science, as well as learning how to develop arguments and appreciate attitudes as to the direction of science. The authors presuppose History and Philosophy of science (HPS) to be an "integral part of scientific knowledge, and therefore, they must be studied in science courses" (de Carvalho \& Vannucchi, 2000: p. 427).

Secondly, research was also done by Galili and Hazan (2000) in Israel. The influence of a historically oriented course on students' understanding investigated the effects of a one-year optics course that incorporated historical materials about light and vision models on students' perceptions about the NOS and technology and the extent of subject knowledge. HPS was introduced through historical texts in terms of drawing parallels between the students' conceptions and historical conceptions of the concepts of light and vision, although no specific teaching strategy was suggested to the teachers who ran the course.

Understanding that these studies presented favorable results about the importance of teaching of the NOS, we looked for essential teaching strategies to deliver effective lessons since teaching of the NOS is not always effective: simplistic or erroneous conceptions of science sometimes persist and unfortunately, we have students coming to the $\mathrm{PhD}$ level not understanding the nature of science and studies have shown that, among children, adults, science teachers, and even scientists, an understanding of the NOS is meagre at best. For example, 70\% of the American adult respondents to the 2001 National Science Board Survey of Public Attitudes Toward and Understanding of Science and Technology did not hold an adequate "understanding of the scientific process" (National Science Board, 2002). Comprehending these problems which are associated with teaching the nature of science (NOS) is considered a vital component of scientific literacy worldwide (e.g., American Association for the Advancement of Science, AAAS, 1990; Lederman et al., 2002; Millar \& Osborne, 1998; Osborne et al., 2003; Wahbeh \& Abd-El-Khalick, 2014).

Abd-El-Khalick and Lederman (2000) distinguish between implicit and explicit approaches to NOS instruction: Implicit NOS instruction assumes that 
students can learn the NOS target as a side effect of the learning experience. Aspects of the NOS can be addressed to students by "doing science". Students engage in science-based activities, but NOS issues are not specifically addressed. In contrast, explicit NOS instruction takes NOS learning to be a direct target, not a side effect of the learning experience and aspects of the NOS are directly addressed with students. SCOL 270 is a course exploring the nature of science as a direct target (explicit NOS instruction). In this course there were 26 sessions in total and students had one 3-hour class per week.

In the search for proper strategies to deliver adequate understanding of the NOS, we considered an experiment in a calculus-based introductory physics course on optics and modern physics reported by Kalman (2002, 2010). In Kalman's study, students study one philosopher all semester as a group project and report regularly on how their philosopher would view the subject matter of the course. Students were asked about their views at the beginning and end of the course, they also had essay questions about the NOS on the midterm and final examinations. Students submitted five essays about the philosopher of science that they were following during the course. It was found that the course had a strong influence on students' views of the NOS in that many students changed their views about how theories evolve. The students seem to have made a marked improvement in their understanding of NOS and in their grasp of the underlying concepts of the subject matter of the courses. Relying on the results of Kalman's project, we decided to use student-centered strategies in SCOL270. Similar to Kalman's project, we exploit usage of evaluating modern philosophers of science and students submitted reflective writings and critique essays each week. In addition, some other strategies were used in SCOL270; "reacting to the past" role-play approach and class discussions. A previous study to show effectiveness of the use of debate to provoke learning about the NOS is reported by Simonneaux (2001). This paper compares the impact of role-play and a conventional discussion on students' argumentation on an issue involving animal transgenesis.

Further support of these strategies can be found in Rudge \& Howe (2009). In their studies, Rudge and Howe have applied similar techniques by encouraging students to adopt the thinking habits of historical scientists. In their model, students reflect on perspectives developed within the classroom, prompted by evidence and considerations introduced by the instructor to help students engage in the sort of reasoning that led past scientists to develop their insights. On our model, in contrast, students go through an immersive experience about the life and times of scientists of a specific era by role playing characters. The interactive nature of this strategy can capture students' interest and provide an engaging way to explore new viewpoints.

\section{Purpose of the Study}

The purpose of this study is to investigate the effectiveness of teaching the Na- 
ture of Science (NOS) in a student-centered classroom, specifically SCOL 270, a 6-credit course on the historical, philosophical, and social aspects of science. This course considers the intellectual framework of science and the relationships between science and society, and the political and philosophical questions inherent in the scientific process. Students are expected to understand the scientific issues at the level at which they were originally addressed. For most students, this was their first course in which the NOS was addressed. In order to foster critical thinking and to equip students with essential cognitive and communicative skills, a combination of student-centred instruction methods are used, including "reacting to the past" role-play, inquiry-based debates, reflective writing and the course dossier method. This study explores changes in students' understanding about the NOS. Through systematic analysis, themes were generated and comparisons between pre- and post-course data demonstrate improved and deepened NOS views that are more aligned with the NOS literature, and a greater number of rationales for including NOS in the curriculum.

\section{Theoretical Framework}

What is science and scientific knowledge? Are scientific laws and theories discovered from nature? Or, are they invented by scientists and their community?

The discipline of the Nature of Science (NOS) seeks to answer these questions. It deals with the epistemology of science, science as a way of knowing, or the values and beliefs inherent to the development of scientific knowledge (Lederman, 1992). There are many different points of view to answer these questions. Here, we provide some these points of views about the NOS which are discussed in SCOL 270. All the following material was taught to students using student-centred teaching and in section 5, we'll see a major influence of these three philosophers on student's understanding of science:

\subsection{Popper's Philosophy of Science}

The first modern philosopher of science who was discussed in SCOL 270 was Popper. Students wrote Reflective Writings and critique essays about the Popperian points of view and they engaged in group discussions about his philosophy of science. Karl Popper's philosophy of science uses modus tollens as the central method of disconfirming, or falsifying, scientific hypotheses. Scientists start with a current scientific theory and use the usual methods of deductive reasoning to derive specific conclusions, of which some are "predictions" (Popper, 1992). Strictly deductive reasoning is "truth preserving", that is, it is such that if one starts out with "true" premises, one can only deduce "true" conclusions. Starting with a "theory" and deducing "predictions" can be stated in the form of a premise:

If the theory is true, then the prediction is true.

Popper shows that we cannot prove that a theory is true, but we can certainly show that a prediction is false. If the scientist tests one of these predictions and 
finds out that it is not true, he uses modus tollens to conclude that the theory cannot be true:

If the theory is true, the prediction is true.

The prediction is not true.

Therefore, the theory is not true.

In Popper's view a scientific theory should be falsifiable, testable and refutable (Popper, 1992).

\subsection{Bacon's Philosophy of Science}

Francis Bacon was also discussed in SCOL 270. Bacon has a more empirical point of view about scientific knowledge. In order to test potential truths, or hypotheses, Bacon devised a method whereby scientists set up experiments to manipulate nature and attempted to verify their hypotheses (Bacon, 1863). For example, in order to test the idea that sickness came from external causes, Bacon argued that scientists should expose healthy people to outside influences such as coldness, wetness, or other sick people to discover if any of these external variables resulted in more people getting sick. Knowing that many different causes for sickness might be missed by humans who are unable or unwilling to perceive them, Bacon insisted that these experiments must be consistently repeated before truth could be known: a scientist must show that patients exposed to a specific variable more frequently got sick again, and again, and again. He believes in a direct engagement with nature as he argues:

"All depends on keeping the eye steadily fixed on the facts of nature".

Bacon encourages scientists to travel over the earth collecting facts, until the accumulated facts reveal how Nature works.

\subsection{Thomas Kuhn: Dynamics of the Nature of Science and Educational Reforms}

Thomas Kuhn's idea that scientific revolutions come in phases changed the way the world thinks about scientific progress and the nature of science. The conclusion that Kuhn drew was that the nature of scientific process was non-cumulative and rather circular going through phases of normal science, crisis, and revolution. The central tenet of his book, The Structure of Scientific Revolutions, introduces the idea of paradigm - an intellectual disciplinary framework which makes research possible. Researchers engage themselves within this paradigm through a puzzle-solving attitude (dubbed "normal science") to bridge the discrepancies between predictions and observations. Over time, anomalies may accumulate leading to a crisis and a paradigm shift. This is a very different approach as opposed to the views of realists like Popper, to whom science is primarily concerned with problem-solving, innovation and exploration.

A tempting question to ask now is whether educational reforms in science can be understood as paradigm shifts through a Kuhnian lens. According to Kuhn, normal science education is a form of indoctrination as students are initiated into the dominant paradigm of the day by their educators and the methods and 
content of the paradigm are accepted without questioning (Kuhn, 1963: p. 357). The only way to graduate to another paradigm is to forsake the traditional methodologies as normal science is marked by a lack of debate on the basic concepts (1970: p. 6). Continuing with Kuhn's analogy, such a paradigm shift would trigger a resistance on the practitioners' side. It can be argued that the major reason for the resistance to change on the teachers' side could be the difficulty (if it is not impossibility) for teachers to comprehend the conceptual framework of the reform (or the new paradigm) as this requires denying the previous educational context in which they established themselves. Fullan (1991) argues that the core values developed by individuals over time regarding various aspects of education are difficult to change as such values are "often not explicit, discussed, or understood, but rather are buried at the level of unstated assumptions" (p. 42). As is the case, that the greatest resistance would come from the more experienced teachers, whereas the new teachers may be more open-minded.

\section{Design of SCOL270}

Student-centered instruction (students' active involvement in the learning process) may be important in teaching the NOS. Empirical studies have confirmed that students report high perceived needs satisfaction when taught in a student-centered way (Minnaert, Boekaerts, \& de Brabander, 2007; Müller \& Louw, 2004; Smit et al., 2014).

Claims are made that teachers talk too much in the classroom, and that it is essential to minimize teacher talk and increase learner talk (Kennedy \& Barnes, 1994). Following methods were used in SCOL270 in order to engage students in the process of learning:

\section{1. "Reacting to the Past" Role-Play: Living History and Learning through re-Enactment}

The simulation of history has interesting consequences resulting in participatory inquiry. The concept of reacting to the past (RTTP) was first implemented by Carnes (2014) at Columbia University, as a technique where students go through an immersive experience about the life and times of scientists of a specific era by roleplaying characters. This pedagogical technique actively engages students to understand and analyse situations while critical thinking becomes automatically a part of the entire process. Jacob Moreno, a psychologist from the 1900s, aptly uses the term "psychodrama" to best describe this interactive approach. Activities similar to Moreno include Cakici \& Bayir (2012) which is another attempt to use drama to support students' learning about the NOS. In their research, the authors concluded that role play positively influences students' views of the NOS and it allows students to express their understanding in a collaborative fashion.

In RTTP, class sessions are run entirely by students who play it like a game scene and instructors advise and guide students and grade their oral and written 
work. Before the theatrics, students have to extensively go through the texts to understand scenes and scenarios. Students are encouraged to write essays on what they understood of the content, which establishes a solid background on sense making of what they are about to do.

Particular examples, which were carried out at SCOL 270, were the Trial of Galileo game (GG) and the Darwin game (DG). In the trial of Galileo students enacted the whole scene in which Galileo had to face the consequences for introducing new ideas differing from the accepted views. In the Darwin game, students were assigned to groups of conservatives and to groups of more liberal characters. They discussed Darwin's grand idea of evolution by natural selection and whether the Copley medal (a scientific award given by the royal society for outstanding achievements in science) should be given to him or not. Students had to engage in a debate which encourages their fact building skills using logical arguments.

\section{The Role-Play Situation}

The teacher distributed labels on which were written the names and the role specification of the participants. At the beginning of the role-play, each student had an individual presentation to discuss his/her role and give a summary of the character. While the role-play was underway, the teacher was responsible for the timing and asking students to vote at the end. Students were assigned to read the textbook and articles related to their role at home. During the role-play exercise, students developed their own lines and actions.

\subsection{Reflective Writing (RW)}

Reflective writing is a student-centered approach widely used in science and engineering courses that helps students to go through a conceptual change (Huang \& Kalman, 2012).

Students come into science classes with their own perceptions and beliefs. They have great difficulty reading scientific texts. The language and epistemology of science is similar to a foreign culture (Kalman, 2011) Based on the hermeneutical perspective in science education, there exist two horizons (Gadamer, 1975: p. 272). One that contains everything that students believe, and the other horizon encompasses all the textual material. Gadamer (1975: p. 269) defined the horizon as "the range of vision that includes everything that can be seen from a particular vantage point." A new horizon, that is, understanding or experience is created by the "linguistic" fusion of the subject matter of the interpreter and object matter of the text within the hermeneutical event (Porter \& Robinson, 2011).

Step 1: When students read the text, they build their new horizon. This horizon is the combination of student's parts i.e. the student's pre-understanding, experience from their life world and experience from the text book. This is the student's whole. The text whole is a combination of its parts (Khanam, 2014) (Figure 1).

Step 2: When students are looking at a particular part of the textbook that they are trying to understand, they refer to their entire understanding. It is their 
understanding from the viewpoint of this particular part of the textbook. In reviewing the particular part again, they may discover contradictions. In this case, their horizon shifts in the direction of the horizon projected by the textbook. This is the back-and-forth movement of the hermeneutical circle. As they go along and make corrections their horizon shifts in the direction of the horizon projected by the textbook (Figure 2). Reflective writing helps the students' horizon to come closer to horizon of the textbook (Kalman, 2011).

Before covering the material in class, the teacher would ask the students to read the material in their textbooks, as homework, then to write and reflect about what they have read (Connally \& Vilardi, 1989). Students were asked to notice four features which should be presented in the reflective writing product. First, it should be presenting the key concepts of the subject as understood by the student. Second, it should be describing the relationship between the various concepts. Third, students should relate the key concepts to their own life experiences. Fourth, students should formulate their own questions.

\subsection{Critique}

After a class discussion, students were asked to write a one-page post-summary (critique) of the discussions occurring in the class of the week.

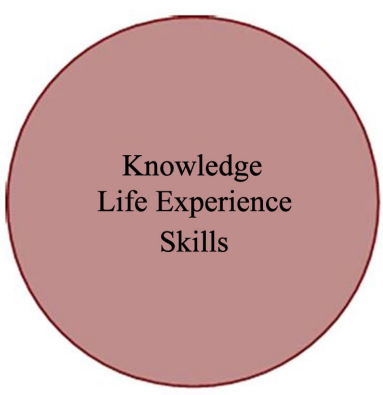

Student's horizon

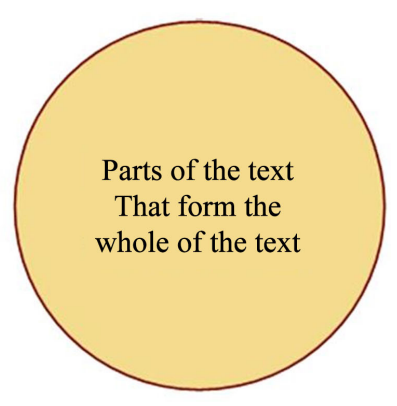

Text's horizon

Figure 1. Horizon "A" of Students and "B" of Author's Horizon of the Textbook (Khanam, 2014).

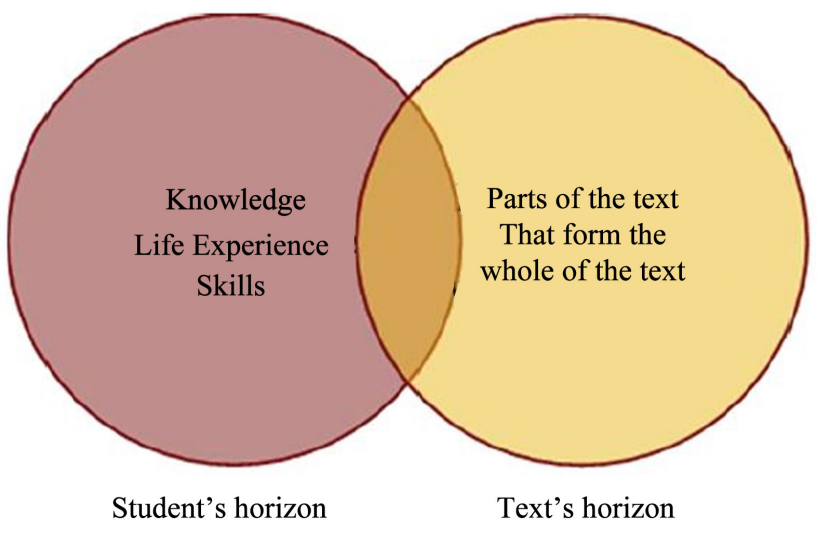

Figure 2. Students' horizon shifted to the horizon projected by the text (Khanam, 2014). 
The critique has various forms: for science students in a regular science course it would likely consists of a short introductory paragraph, followed by a presentation of what was covered in the class of the week and in a course for non-science students, it would be a one-page essay. The essay would be written in a format that anyone who knows no science can understand. In writing the essay the students pick one or two of the most important concepts from the lectures presented in the class in that week and then critically analyse those concepts in the rest of the paper. The critiques must be presented in properly written paragraphs using normal writing or $12 \mathrm{pt}$. font and as few equations as possible. The students are warned that marks are deducted for unnecessary use of mathematics and extra pages are not read (Kalman et al., 2008).

In SCOL270, a one-page critique is written that consists of the concepts that were covered in the class discussion between students including the professor's short lectures that were given at the end of the class.

\subsection{Inquiry-Based Debates}

Empirical research on classroom practices notes the importance of teachers framing connections between everyday knowledge and scientific knowledge, rather than treating content as entirely new and disconnected from other learning contexts (Bransford \& Schwartz, 1999; Cornelius-White, 2007; Littleton \& Mercer, 2013; Erstad \& Sefton-Green, 2012).

Group discussion is useful to frame these connections and encourage students to evaluate material critically. Having performed Reflective Writing, students are familiar with the subject matter. The teacher would divide students into 4 groups. Two groups would debate two different points of view related to the subject matter and a third group would design questions to ask them. The fourth group is in charge of evaluating the pros and cons of each argument and decide the winner of the debate. Each group had 5 minutes to think and discuss the question and then they had 10 minutes to present their argumentations. When we interviewed students about what criteria they would consider to choose one group's argumentation over the other, they mostly considered whether the argumentation was well-responded and included diverse arguments that held the most weight. They suggested that if one group kept saying the same point, they wouldn't vote for it.

For example, there was a debate as to whether or not hypnosis can be regarded as a scientific phenomenon. One group discussed supports of the hypnosis that this phenomenon is caused by voluntary actions in an altered state of consciousness. The other group argued that hypnosis merely "works" via the power of suggestion which can affect both thoughts and behaviour.

\subsection{Course Dossier Method}

The Course Dossier Method (Khanam \& Kalman, 2017) is a writing-to-learn tool. The idea of the course dossier method is to use writing procedures based 
upon Gadamer's hermeneutical approach (Gadamer, 2004) and scaffolding using student reviewers based upon social constructivism (Vygotsky, 1978). The idea of Vygotsky's (1978) social constructivism is that the students can construct their scientific knowledge with the assistance of other people. Vygotsky's (1978) notion of "Socio-Cultural" learning and teaching indicates that society is a key norm where students acquire knowledge in many ways- from classroom, family, friends or other social sources. Learning is a process that influences as-acted on by the environment (teacher, family, and friends). According to Vygotsky, learning is considered as an external process. In this process we internalize our individual thinking with others thinking (Wink \& Putney, 2002). Moreover, Vygotsky believed that learning and development of thinking are an interrelated, dynamic process (Wink \& Putney, 2002), because "learning is not development" but properly organized learning causes mental development.

The idea of the course dossier method is also to use writing procedures based upon Gadamer's hermeneutical approach (Kalman, 2018). As explained in section 3.2. The hermeneutical circle is the fusion of the learner's horizon with the horizon of the text. In this method students used different kinds of writing activities (during the course): writing reflections (before students came to class), "Critiques" (after class) and final essay writing (Course Dossier with six entries) at the end of the course in lieu of the final exam. Students are asked to review the critique essays and have their essays reviewed and reflected upon by people who did not attend the course. Using their reflections, they write a single overview of the course content.

\subsection{Summary}

In this section, we explained the design of SCOL270. The course exploited the use of student-centered instruction. Different methods such as RTTP, RW, critique essay and course dossier were used to engage students and bring about deep understanding of NOS in their minds. The different approaches utilized in the course are summarized in Table 1.

Table 1. An overview of implementing different approaches in (SCOL270).

\begin{tabular}{|c|c|c|c|c|c|}
\hline Interventions & RTTP & RW & Critique & Debates & Course Dossier \\
\hline $\begin{array}{l}\text { How often } \\
\text { interventions were } \\
\text { used? }\end{array}$ & $\begin{array}{l}\text { both semesters } \\
\text { (GG in the first } \\
\text { semester and DG } \\
\text { in the second semester) }\end{array}$ & Both semesters & Both semesters & Both semesters & $\begin{array}{l}\text { End of the second } \\
\text { semester }\end{array}$ \\
\hline $\begin{array}{l}\text { in what order } \\
\text { interventions were } \\
\text { applied? }\end{array}$ & $\begin{array}{l}\text { First } 5 \text { classes of the } \\
\text { first semester and first } 5 \\
\text { classes of the second } \\
\text { semester }\end{array}$ & $\begin{array}{l}\text { One RW per session } \\
\text { (which means one RW } \\
\text { assignment per week) }\end{array}$ & $\begin{array}{l}\text { One critique per } \\
\text { session (which } \\
\text { means One critique } \\
\text { assignment per week) }\end{array}$ & $\begin{array}{l}\text { Classes started with a } \\
\text { discussion activity then } \\
\text { it was followed by the } \\
\text { professor's lecture }\end{array}$ & $\begin{array}{l}\text { Each student } \\
\text { submitted a course } \\
\text { dossier at the end of } \\
\text { the second semester } \\
\text { (there was no final } \\
\text { exam) }\end{array}$ \\
\hline
\end{tabular}




\section{Methodology}

The science college course titled Historical, Philosophical and Social aspects of science (SCOL 270) is a two-semester course offered every year at Concordia University. This course was first examined in Fall of 2015-16 by Baptiste Roucau. The class consisted of 20 science undergraduate students in that year. Students were mostly in their first year enrolled in honours programs in biology, chemistry, physics, mathematics, psychology and the department of health, kinesiology, and applied physiology. He participated in all the classes and interviewed six students enrolled in the course at the beginning and end of the first semester. A second researcher, Fereshte Heidari, examined the course in 2016-17. She participated in the same course in both semesters and interviewed six of the 19 students enrolled in 2015-16 at the beginning and end of the second semester (Winter semester). Overall 12 students were interviewed (one student withdrew from the 2015-2016 participants) and 4 sets of interviews had been carried out. A summary of the whole design of the project can be seen in Figure 3.
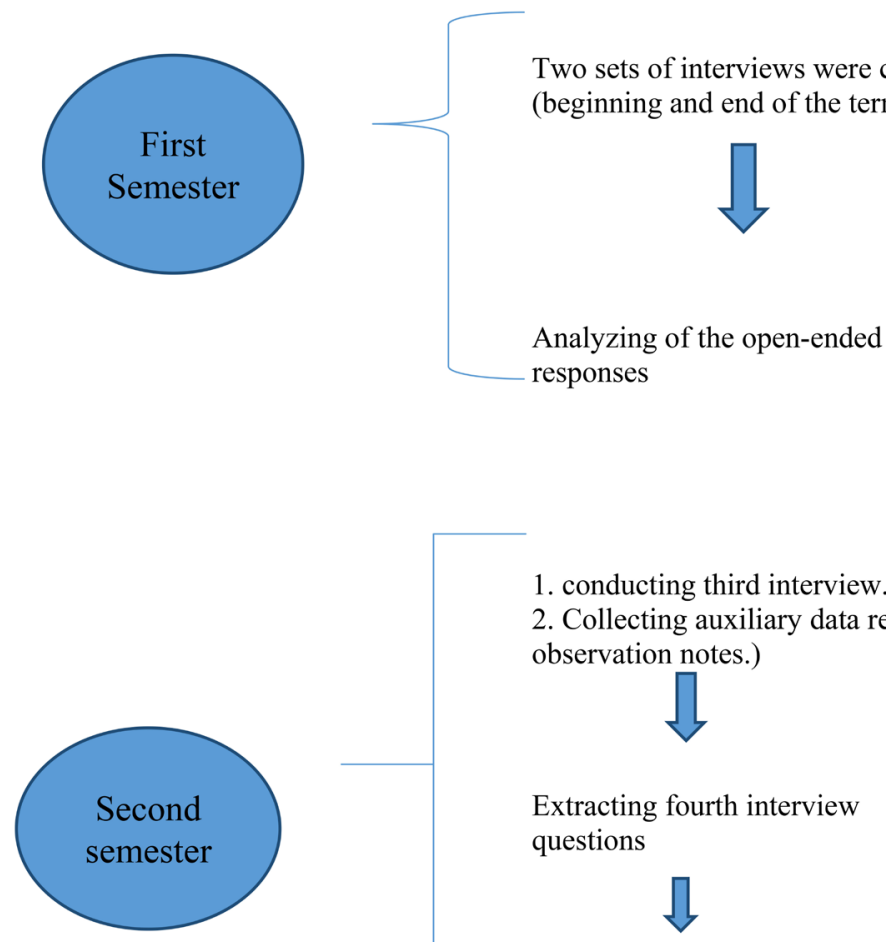

1. conducting third interview.

2. Collecting auxiliary data resources (students assignments, observation notes.)

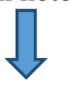

Extracting fourth interview questions

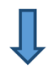

end of the semester: Semi-structured interviews.

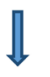

Analysis of the interview data (comparison with data collected from observation and students' assignments)

Figure 3. Research design and procedure. 
To blend the data from both researchers the same questions from the end of the first semester in the 2015-16 (first year of running the project) were used in the beginning of the second semester of the 2016-17 course (second year of running the project). The research project was overseen by a senior researcher, Calvin Kalman, for both courses. Both courses were taught by the same instructor, who was not part of the research team and who taught the course in an identical manner both years.

There were two levels of participation in the study:

The first level of participation for all students. Participants were asked to agree to being observed in the classroom by the investigator. They were asked to agree to have their essays, reflective writings and course dossier assignments analysed by the investigator after they have been graded by the instructor.

Second level of participation for students who agreed to be interviewed. In addition, students who have agreed to take part in interviews were interviewed for approximately forty minutes at the beginning and at the end of the semester by the investigator.

Since surprisingly all the students in the course agreed to participate in both levels of participation, we had the chance to choose between the students. The conditions for selecting interviewees were diversity in their field of their studies as well as their genders.

\subsection{Qualitative Inquiry Approach}

Multiple case studies were used in this research and each student is taken as a case. Case-study research builds an in-depth, contextual understanding of the case, relying on multiple data sources (Yin, 2018). In a collective or multiple-case study, the researcher selects one issue or also selects multiple case studies to illustrate the issue and to show different perspectives on the issue (Creswell, Hanson, Clark Plano, \& Morales, 2007).

Interviews are the most important method of data collection in case studies. Semi-structured interviews allow researchers a more comprehensive understanding of students' views, reasons and resources informing the beliefs that students have and the way in which students' views affect their learning (Aikenhead, 1987; Lincoln \& Guba, 1985). Semi-structured interviews in this study brought an in-depth understanding of participants' points of views on the NOS.

Observation was conducted in an ethnographic manner described by Creswell $(2009,13)$. We took notes on students' views during role-play argumentations as well as inquiry debates. However, the data collected from observation was very limited and used only for the purpose of triangulation of data.

Therefore, in total three methods of data collection were used:

a) Their answers to questions in a semi structured interviews (Merriam, 1998) and b) The writing products of the participants, c) data collected from in class observation.

Qualitative methods (Creswell, Hanson, Clark Plano, \& Morales, 2007; Greene, 
Caracelli, \& Graham, 1989; Yin, 2018) were used to analyze the data. More specifically, we used open coding and protocol analysis for all the transcripts, assignments and observation notes (Priest, Roberts, \& Woods, 2002). Table 2 presents the research questions and a summary of related data sources as well as analytical methods.

\subsection{Validity of the Research}

Triangulation was used to establish credibility. Triangulation refers to the use of multiple methods or data sources in qualitative research to develop a comprehensive understanding of phenomena (Patton, 1999). Triangulation also has been viewed as a qualitative research strategy to test validity through the convergence of information from different sources. Denzin (1978) and Patton (1999) identified four types of triangulation: 1) method triangulation, 2) investigator triangulation, 3) theory triangulation, and 4) data source triangulation. The current study benefited from data source triangulation.

To promote the credibility of the study, triangulation was utilized between three data sources (Figure 4); observation of the class in 26 weeks (throughout fall and winter semesters) reflective writing assignments and interviews. Moreover, the results of the analysis of Reflective Writing products were compared to the results of the interview analysis to assess whether they corresponded or conflicted with each other.

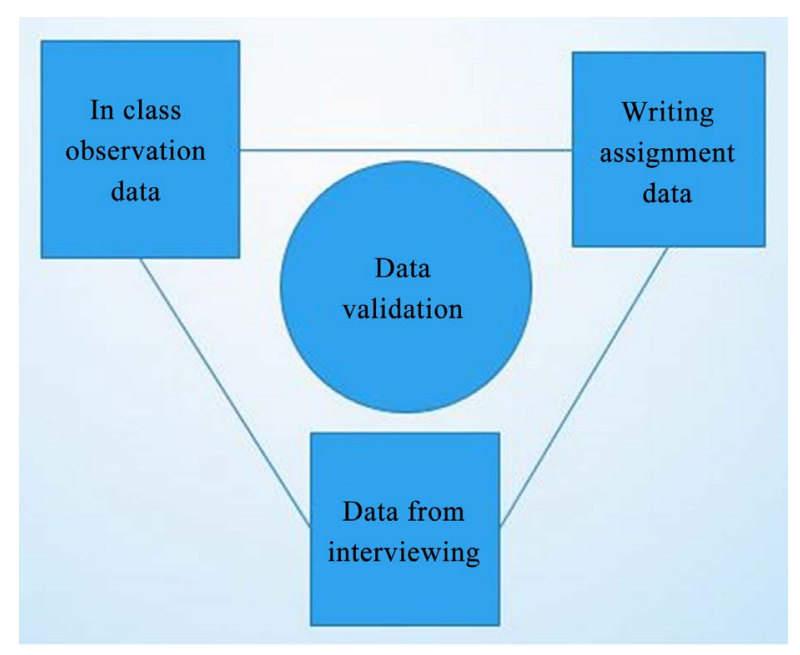

Figure 4. Triangulation method.

Table 2. Research questions, Data and Analysis.

\begin{tabular}{|c|c|c|}
\hline Research Question & Data & Analysis \\
\hline $\begin{array}{l}\text { Does studying Nature of science in a } \\
\text { student-centered classroom change students' } \\
\text { conception of Science? }\end{array}$ & $\begin{array}{l}\text { - } \quad \text { Students' interviews } \\
\text { - } \quad \text { Observation notes }\end{array}$ & $\begin{array}{l}\text { a. Coding (identifying major themes emerging } \\
\text { from the texts or identifying themes based on } \\
\text { literature review and concepts discussed in class }\end{array}$ \\
\hline $\begin{array}{l}\text { Purpose: To identify effectiveness of teaching } \\
\text { NOS in a student-centered class }\end{array}$ & - $\quad$ Students' assignments & $\begin{array}{l}\text { b. Listing } \\
\text { c. comparing themes and making conclusions }\end{array}$ \\
\hline
\end{tabular}




\section{Results of the Qualitative Data Analysis}

This qualitative data provides in-depth understanding of the students' conception of the NOS. Common themes are grouped together, and the students' opinion about their evolving understanding of the nature of a scientific theory is reported. The crucial point of the interviews was to identify the impact of student-centered teaching on students' understanding of science. Open coding analysis is used for this part of project in which the themes or categories emerge from the responses (Priest, Roberts, \& Woods, 2002). Protocol analysis is used for this part of the project in which responses are coded according to predetermined categories, for example, who mentioned paradigm shift (Priest, Roberts, \& Woods, 2002).

\subsection{Responses to the Interview Questions (First Semester)}

The semi-structured interview questions for this study were designed to evaluate students' conception of science. Interviews allowed us to compare students' attitudes towards NOS at the beginning of the fall semester with how they define their view of science in the post-interview. They explained their views of science and talked about the changes in their ideas during the semester. In the post-interview, all interviewees except for student are mentioned that they no longer thought that science was straightforward. All interviewees experienced changes in their understandings about science during the semester. They all believed that the Galileo Game had a positive role in understanding how science works.

Table 3 is the summary of the analyzed data of the interviewed (first-semester) students.

From Table 3, we see that the students JU and NO and FR found weekly RW assignments helpful. They did not miss any RW during the semester. We can see at the end of first semester, they were aware of subjectivity of science and effects of society on science. For HA and GA, the Galileo Game was very useful, based on analysis they no longer thought science was straightforward and they understood how religion can affect the progress of science. Most of the students understood that science is not just the matter of random experimentation and that science is a complicated process. Students' conception of science improved during the first semester.

Students JU, FR, and HA mentioned that science progresses through observation and experimentation. During the post-interview they all mentioned many factors, such as historical and social factors that affect the science process. In the pre-interview student NO explained that scientists go from the questions they have in their mind and the things they know which they use to develop a hypothesis. In the post-interview student NO explained there was a change in his attitude: "Science is a much more complicated process than I thought! Because it's not only creating an experiment and a hypothesis and testing things and getting results and then putting those results into words. It's not like that. I think 
the biggest factor is our own society." All interviewees understood the scientific issues and the relationship between science and society.

Furthermore, to blend the data from both researchers the same questions from the end of the first semester in the 2015-16 course were used in the beginning of the second semester of the 2016-17 course. The data collected from the participants in this project (group 1) was compared to the data collected from previous students in the same course (group 2). Having data from the 2015-16 course also provided some conceptual clarification for the research design as well. It helped to refine the data collection plans for the winter semester for the 2016-17 course. We were indeed able to show the same pattern in student's conception of science for both groups which added to the reliability of the research.

\subsection{Responses to the Interview Questions (Second Semester)}

Table 4 is the summary of the analyzed data of the interviewed students (second semester).

From Table 7, we can see that some students changed their attitude towards the Nature of Science. Some students did not change their views but they were able to give better explanations of their conceptions of science.

Table 3. A Summary of the Analyzed data of Interviewed Students (First Semester).

\begin{tabular}{|c|c|c|c|c|}
\hline Case & Earlier in the semester & Later in the semester & $\begin{array}{l}\text { students' personal experience of } \\
\text { the course }\end{array}$ & $\begin{array}{l}\text { Methods that students' find } \\
\text { helpful }\end{array}$ \\
\hline FR & $\begin{array}{l}\text { She saw science as an objective } \\
\text { entity with straight forward } \\
\text { methodology. }\end{array}$ & $\begin{array}{l}\text { She explained that scientists are } \\
\text { motivated by social demands. } \\
\text { They are influenced by society. }\end{array}$ & $\begin{array}{l}\text { The course challenged her to } \\
\text { think things she has never } \\
\text { thought before. }\end{array}$ & $\begin{array}{l}\text { RW papers allowed her to } \\
\text { analyses how science works. By } \\
\text { analyzing the works of different } \\
\text { authors, she got involved with } \\
\text { material of the course. }\end{array}$ \\
\hline HA & $\begin{array}{l}\text { He saw science as a general } \\
\text { wondering and trying to } \\
\text { look for answers about } \\
\text { everything around us. }\end{array}$ & $\begin{array}{l}\text { Discovered many factors, like } \\
\text { historical and social factors that } \\
\text { affect the science process. }\end{array}$ & $\begin{array}{l}\text { She explained in this course it } \\
\text { wasn't really about memorizing, } \\
\text { it was more like creating. It really } \\
\text { helped her to understand see how } \\
\text { scientists made their discoveries. }\end{array}$ & $\begin{array}{l}\text { Class discussions, Galileo Game } \\
\text { helped her a lot in order to } \\
\text { vunderstand how science works. }\end{array}$ \\
\hline GA & $\begin{array}{l}\text { Saw science as the laws of } \\
\text { nature and trying to } \\
\text { understand how the world works. }\end{array}$ & $\begin{array}{l}\text { Being aware of social factors } \\
\text { and embodiment of historically } \\
\text { influences in science. }\end{array}$ & $\begin{array}{l}\text { He thought the course was } \\
\text { beneficial for him Because } \\
\text { students shouldn't spend all } \\
\text { their time learning theorems or } \\
\text { learning laws. He thought that } \\
\text { philosophy in general is very } \\
\text { important to every student. }\end{array}$ & $\begin{array}{l}\text { Galileo Game helped him } \\
\text { rewriting and researching the } \\
\text { subject matter all the time and } \\
\text { make him prepared for the class. }\end{array}$ \\
\hline NO & $\begin{array}{l}\text { She explained science is } \\
\text { only about hypothesis and } \\
\text { experimenting. }\end{array}$ & $\begin{array}{l}\text { She was aware of the fact } \\
\text { that expectations of the culture } \\
\text { determine what to study. }\end{array}$ & $\begin{array}{l}\text { Despite other courses, this course } \\
\text { wasn't about memorization. It } \\
\text { was about making links, } \\
\text { researching and understanding. }\end{array}$ & $\begin{array}{l}\text { RW papers helped her to be } \\
\text { prepared in advanced for the } \\
\text { class and helped her to be highly } \\
\text { engaged. }\end{array}$ \\
\hline JU & $\begin{array}{l}\text { Saw theory evolving through } \\
\text { observation. }\end{array}$ & $\begin{array}{l}\text { Understood the biases in } \\
\text { science progress journey. }\end{array}$ & $\begin{array}{l}\text { Learning about history of science } \\
\text { was very useful to understand } \\
\text { how science works and how } \\
\text { theories evolve. }\end{array}$ & $\begin{array}{l}\text { RW and GG were very useful } \\
\text { since they helped her to interact } \\
\text { better. }\end{array}$ \\
\hline
\end{tabular}


Table 4. A Summary of the Analyzed Data of Interviewed student (second semester).

\begin{tabular}{|c|c|c|}
\hline Research Questions & Case & Students' Approach \\
\hline \multirow{5}{*}{$\begin{array}{c}\text { Does studying Nature of } \\
\text { science in a student-centered } \\
\text { classroom change students } \\
\text { conception of Science? }\end{array}$} & FN & $\begin{array}{l}\text { She had changed her attitude about the NOS and explained that science changes in the } \\
\text { manner of a paradigm shift as described by Kuhn. }\end{array}$ \\
\hline & $\mathrm{KB}$ & $\begin{array}{c}\text { At the end of second semester Her response as to how theories come about followed that } \\
\text { of Popper. }\end{array}$ \\
\hline & GL & $\begin{array}{l}\text { He thought that the process of changing theories } \\
\text { is really slow moving and eventually a new paradigm slowly } \\
\text { replaces the old one. Theories change in the manner described by Kuhn. }\end{array}$ \\
\hline & $\mathrm{MC}$ & $\begin{array}{l}\text { This student's views of science didn't change but she was able to give a much clearer } \\
\text { exposition of her Baconian views. }\end{array}$ \\
\hline & SM & $\begin{array}{l}\text { He explained the Kuhnian point of view that when new theories come about, there will be } \\
\text { a resistance from the scientific community as happened in the time of Galileo. }\end{array}$ \\
\hline
\end{tabular}

\subsubsection{Student FN}

In the first interview, in response to the question on how scientific knowledge evolves, she stated that science would be always the same and she can't see it in a different context:

"I think the fundamental science would be the same, no matter who we are. I feel like science would always be the same. I don't see it in a different context or different rules." In her reflective writing assignment student FN explained her understanding of a Kuhn paradigm shift: "The idea that scientists need to have a paradigm to discover things seems off. Shouldn't it be possible for someone to just decide to explore even though this is not the norm something that piques their curiosity and still come to the same conclusion as someone who would have encountered a problem to reach that conclusion."It seems that she critically evaluated Kuhn's point of view and challenged the idea of a paradigm shift. However, on the last day of the course, in responding to the question of how scientific theories evolve, she changed her attitude about the NOS and explained that science changes in the manner of a paradigm shift as described by Kuhn: "scientific theories have to go through that phase of resistance pretty much like in Darwin and Galileo. ... you have to have tribulations kind of like a paradigm shift. There's a crisis and you have those big debates going on. So, it's like a Circle event that happens I feel like it's a pattern but the way it plays out won't necessarily be the same in both. I feel like with Galileo he was in court but it's pretty much the same thing that happened with Darwin with just like scientist debating." She also showed an impressive change in her conception of science. The pre-interview transcript showed that she thought for science she should rely on her teachers and books and what is presented to her. The post-interview showed that she didn't think science is straightforward anymore: "Science is not just like: okay! Here is a question and I solved it this is the answer that I want." she also stated that:

"Before I just thought of it like going to school but now I have a different perspective. It is not as simple as you think. You think that you just do science but 
actually, there are many factors."

She came to realize that science has a multidisciplinary nature as she also explained that there are so many little things that influence science which we need to take into account.

\subsubsection{Student KB}

In the pre-interview, student $\mathrm{KB}$ explained that scientific knowledge always changes. Using the example of Dalton's atomic model she explained that all theories are not necessarily true in every aspect and that is why they go through changes. She believed that when we find something that really doesn't fit the current model then we have to find a new model to explain it and that is how scientific theories progress. She also considered science as a collection of knowledge: "Science is a collection of knowledge that people built together sometimes tearing each other down but also building each other up to come to this agreement on what people think about how the world works." In the post-interview, she explained that science is influenced by so many things such as culture, religion and society. She also stated that these influences drive what kind of science should be done and what kind of results are acceptable.

She confirmed that before this course she saw science as an objective mathematical field:

"before I saw it as an objective mathematical field now I realized, it got a lot of influences in more social aspects such as history, philosophy, politics and religion as well." In summary, based on the pre- and post-interviews the course helped to change student KB's conception of science. She initially saw science as a collection of facts but at the end, she was aware of many factors that influence science: "I really liked the pure philosophy when we looked at Kuhn and Paradigm changes and Popper when see that these are just induction and objectivity or something that were kind of brought to science and it didn't necessarily come naturally. It was more we decided that this was what science meant but ... we still follow ... [the] inductive model and this objectivity kind of models that they have ... maybe science isn't as perfect as expected to be. So, it's really changed my views." Her response as to how theories come about followed that of Popper.

\subsubsection{Student GL}

During the pre-interview, student GL explained when older theories, which are not complete, stop working then a new theory takes the place. He was not sure about how the process is made. He also stated that eliminating the human aspects of science helps science progress. In the post-interview, he mentioned that the process of changing theories is really slow moving and eventually a new paradigm slowly replaces the old one. Theories change in the manner described by Kuhn. In the post-interview, he also stated that he used to just see science as a course load in school. Moreover, he used to understand science in a very straightforward manner: "Well, before for me learning about the science involved just opening up a power point and reading sort of basic facts. Now I have 
a more practical view of what learning science is rather than sort of theoretical view." He clarified that the course helped him to understand that what a teacher teaches is just a theory and it is not an "absolute truth". During the post-interview, student GL mentioned that he thinks society can affect science and he also provided a recent example related to his field: "I definitely think that society can affect science cause if we look at more recent examples like how Russia affected its genetics and biologists and forced them to go with inheritance law instead of Darwinian evolution. So, like [in] Galileo times society always plays a massive role."

\subsubsection{Student SM}

In the pre-interview, student SM explained that a lot of science is pretty straightforward except social science. In answer to the question of how theories evolve, he stated that through experimentation we find flaws in the previous theories. In the post-interview, he explained the Kuhnian point of view that when new theories come about, there will be a resistance from the scientific community as happened in the time of Galileo. When student SM was asked to explain his picture of science in the post-interview, he specified that science is not only coming to school and learning certain books and techniques. It is much more complicated in the real world.

In the post-interview, he explained that the course helped him to understand that science is a multifaceted entity: "It is not just science. It is a lot of stuff around it too. You know all the extra stuff that people don't really talk about it all that much; more the issues, more the implications, and certain things. It is all that things around it that involves in science and there is always going to be. It's so broad like lots of research, lots of steps involved like lots of people, where the funding comes from and it's like a multi-disciplinary thing."

\subsubsection{Student MC}

During the pre-interview, student MC explained that science doesn't work in an empirical and systematic way: "I think we like to think that everything is very empirical and systematic and you do the experiment and you see the results and then you have like a fact or like good knowledge, I think sometimes it can differ from that track, I think mainly like research, systematic things though, there are other influences like the pressure of funding agencies. So, basically you do research and you can analyze them and that's it but I don't think it is that clear."

Her response in the pre-interview was that experiment leads to theory but other factors such as personal biases also play a role. In answering the question of how theories evolve in the post-interview, she gave a Popperian response: "When they (scientists) brought up the scientific method, I think they are more specific to certain things. There's less of this universal explanatory power where it's so vague that it can fit into pretty much anything. So, I think when scientists are more critical of what they read and what they look at, theories are more specific and more ... verifiable than some of the previous theories." In the Darwin game discussions towards the end of the course, she also made a good connec- 
tion and used Bacon's argument to challenge her classmates: "So you said that Darwin's theory is scientific because he made a bunch of observations and constructed a theory based on this observation but that is not exactly a scientific method. The Scientific method requires prediction. You have to test these predictions with experimentation that can be repeatable. Could you please explain how can we test the theory of evolution through experimentation?!” In summary, based on the pre- and post-interviews with student MC and also analyzing her attitude in the class discussions, it was concluded that this student's views of science didn't change but she was able to give a much clearer exposition of her Baconian views.

\subsection{Analysis of Non- Interviewed Students}

To show that case studies were representative of the whole class, we analyzed data collected from non-interviewed students.

4 students 2 female and 2 males were analyzed. Students were picked from different genders and different majors. Two sources of data collection were used for non-interviewed students. The first method of data collecting was direct observation since observational evidence is often useful in providing additional information about the topic being studied. The second source was students' assignments. The analytic technique used on data collected for these students was pattern matching. Using pattern-matching compares an empirically based pattern with a predicted one (Trochim, 1989). The patterns coincide with interviewed students which helped to strengthen the internal validity of this study.

Table 5 is an overview of the analyzed data of the non-interviewed students.

As can be seen in Table 5, the data analysis on non-interviewed students is equivalent to that of the interviewed students. In this part of research observational evidence was useful in providing additional information on the non-interviewed students.

\subsubsection{Student A}

Analyzing student A's assignments, some changes were found in her ideas about the evolution of theories as she wrote in one of her assignments that the Popperian point of view touched her and made her think differently:

Table 5. A Summary of the Analyzed Data of Writing Products and observational documents (Non-Interviewed students).

\begin{tabular}{ccc}
\hline Research Questions & Case & Students' Approach \\
\hline $\begin{array}{c}\text { Does studying Nature of science } \\
\text { in a student-centered classroom } \\
\text { change students' conception } \\
\text { of Science? }\end{array}$ & B & $\begin{array}{c}\text { Changes in her ideas about theory evolving were found. } \\
\text { She has a Popperian point of view at the end of the second semester. }\end{array}$ \\
$\begin{array}{c}\text { His ideas about conception of science become } \\
\text { clearer although her attitude towards the NOS did not change. }\end{array}$ & $\begin{array}{c}\text { His concepts of science improved during these two semesters. } \\
\text { He analyzed the progression of science using Popperian philosophy. }\end{array}$ \\
His thinking levels about concepts of science improved
\end{tabular}


"I'm sad to say that I only recently learned that in order for a hypothesis to become a theory, it must undergo tests that attempt to disprove it (not only tests that attempt to prove it right). While this might not overtly seem very important, I have to stress the fact that this means that I didn't truly understand the scientific process, even after having studied it for several years. This lack of understanding on my part has undoubtedly led me to believe that different theories were scientific even though in hindsight, it is blatantly obvious that they aren't. However, by using the criteria outlined by Popper, I can easily tell that Marxism, which I was taught in my first semester in CEGEP [compulsory junior college in Quebec) isn't actually very scientific, given that the theory behind it is vague enough that it can't be disproven (a hallmark trait of pseudo-scientific theories as outlined by Popper)."

Also, in one the class discussions she explained Newton's theory and pointed out that through falsification we can prove this theory is scientific:

"It must be possible to prove the theory wrong through very specific tests. For example, Newton's theory of gravity states that objects with mass must be attracted to each other. This theory therefore states that objects with mass can't repel each other. In effect it "forbids" them from repelling each other. Thus, in order to prove this theory wrong one would simply have to devise an experiment in which objects with mass can be observed to repel each other. Due to these characteristics, Newton's theory of gravity can be considered scientific."

\subsubsection{Student B}

In the first paper assignments this student used a Baconian point of view as she wrote:

"I think scientists are researchers who strive to understand nature. They are unbiased and that they are willing to contemplate different theories in order to find the "truth". A reading of student B's writings made on the last days of the course indicates that this student views became clearer as she found out about different philosophers of science. Yet she didn't inevitably change his views but they became more expert like. In one of the discussions she stated that we never fully understand a concept; we make correlations between observation and what we already know which a Baconian perspective towards the NOS. She also criticized the Kuhnian and the Popperian point of view and felt that these approaches cannot fully define a scientific theory: "While I cannot say that Popper has solved the problem of induction simply through noticing that it exists, I do believe that his criteria for what is and isn't a scientific theory will aid in clearing up this problem. As the saying goes, "the first step to fixing a problem is finding it".

"In my opinion Popper's solution for understanding the character and development of science is invaluable if it is properly used. Kuhn referred to the fact that some scientists might be tempted to modify their experiments and "cheat" in order to prove their theories right. I believe it's safe to say that these theories are not true science and tend to fall into the category of pseudoscience. Thus, 
even though these theories might pass Popper's criteria, due to the fact that they are effectively wrong (as a result of improper observations on the part of the scientists), they still cannot be considered scientific. Thus, I believe that we must ask ourselves what constitutes true science, for neither Kuhn's perspective nor Popper's criteria accurately answer this question."

By comparison of his early and last papers, it's fair to say that her ideas about the conception of science become clearer although her attitude towards the NOS did not change.

\subsubsection{Student C}

Most of his class discussions earlier in the semester showed that he had found out the important concepts covered in the class, but the explanations about those concepts were unclear:

"I think general knowledge is very abstract while scientific knowledge is more science. Since there is science in it, it is more science. General knowledge is more graspable. So, maybe my knowledge is completely different from some one else's knowledge but, since it's science and this is what it is, we may have same scientific knowledge." His later discussions were clearer. In a topic in one of the last classes about hypnosis, he said: "Hypnosis is both experimental procedure and an object of study. The problems around hypnosis in my opinion stem from the fact that it is impossible to say if it is 100 percent science or 100 percent pseudoscience. More research has to be done before hypnosis could be considered a scientific phenomenon". So, he is trying to analyze the phenomenon of hypnosis using Popper's scientific method. He also gave a good analysis of Popper's philosophy of science: "In this discourse Popper attempted to explain away the difference between science and pseudo-science. In order to do this, he focused on the key defining features of scientific theories, namely scientific theories must have a possibility of error; it must be possible to prove the theory wrong through very specific tests. Another defining feature is that the theory must forbid certain things from happening."

The above analysis showed that his concepts of science improved during these two semesters.

\subsubsection{Student D}

Early in the course his writings were more descriptive than conceptual. Later on, he picked up some important concepts, which were covered in the class. In the sixth week he talked about the subjectivity of science and its influences on scientists' researches and he also tried to explain its importance in the field of physics. He wrote: "If you were to ask several different people what they thought scientists were like, the consensus would likely be that scientists are unbiased in their researchers. For example, when doing research, it isn't rare to see a scientist fuss with his tools and equations in order to obtain the results he expected from the start, kind of like how a student might 'accidentally' change a ' + ' to a '-' in an equation in order to make the math come out on a Calculus test. Nor do scien- 
tists easily give up the paradigms they rely on to make their theories."

In this assignment he used a very good analysis of Kuhn philosophy of science. He is referring to scientist's paradigms in a manner of Kuhn. Moreover, some important questions came to his mind that helped him to expand his thought further. For example, upon reading Mermin's The Golemization of Relativity in the eighth week he asked:"If science one day truly does 'golemize', will we be able to stop it or will we be dragged along with it until our inevitable end?"

In the submitted course dossier, he explained this point:

"This is not to say however that there exists no common ground, it is true that biases on the part of others can halt the progress of 'true', progressive science for years (just look at what happened to Galileo, because scientists of the church disagreed with him, he was placed under house arrest for the remainder of his life and told that he could not continue publishing his 'heresy'). Thus while it is true that there can be a problem of golemization in science, it simply isn't as prevalent as Collin and Pinch seem to want their readers to believe."

In conclusion, his thinking levels about the concepts of science improved.

\subsection{Overall Analysis}

Group 1 students (2015-16 cohort) studied in the exact same course with the same professor and methods as group 2 students (2016-17 cohort). Analyzing the two sets of data, we found that the same categories developed in the interview transcripts and students showed the same improvements in their understanding of the Nature of Science.

Here we evaluate three aspects of the NOS which significantly emerged in students' responses to interview questions through open coding analysis. These components of the NOS were addressed in (SCOL270). Different aspects of the NOS are shown in Figure 5.

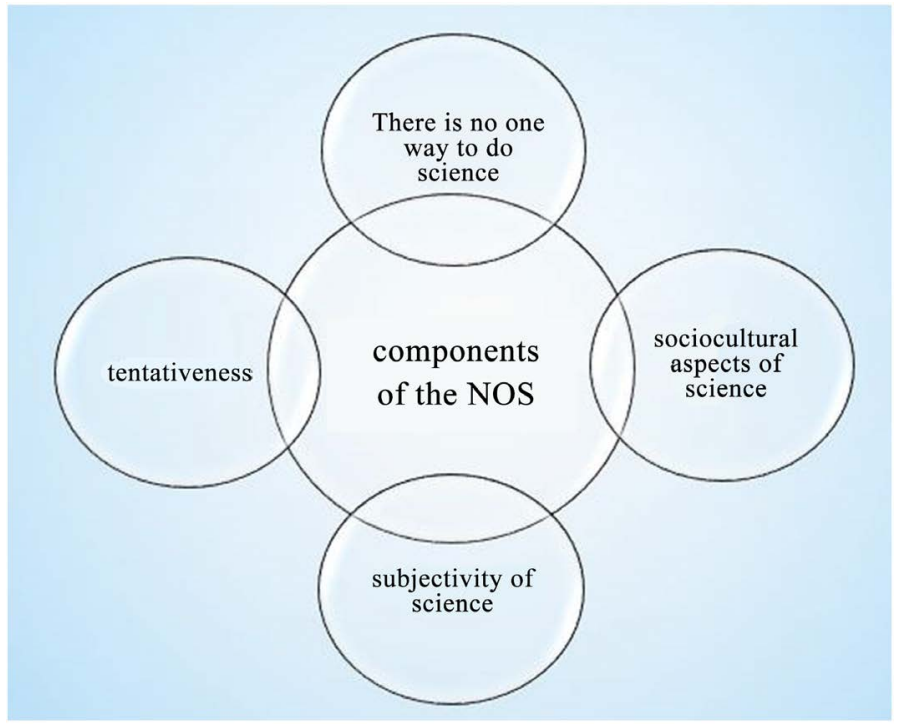

Figure 5. Components of the NOS. 
The result of the analysis is reported in the following order:

1) Common themes though coding of the interview transcripts; 2) Similarities between 2015-16 and 2016-17 participants' understanding of each construct.

Findings are classified into the following sections:

1) Social and cultural aspects of science;

2) Tentative nature of scientific knowledge;

3) Subjectivity.

\subsubsection{Cultural and Social Influences on Science}

Many factors, such as historical and social factors affect the scientific process. In the context of this concept we examine whether students view the scientific enterprise as non-cultural and non-historical, or as multicultural and history-embedded.

Four common sub-categories were extracted from students' responses:

1) The expectations of the culture determine what to study, scientists are motivated by social demands, 2) scientists are members of society, they are influenced by society (education and ways of thinking), 3) Religious background of scientific knowledge, 4) Gender and science.

Most responses showed a multidisciplinary view of science. Society, religion and gender restrict and direct scientists in considering what and what not to study and their personal biases:

As seen in Table 6, common themes emerged for both cohorts. Based on the table most of the students showed progress at least in 2 sub-categories of sociocultural aspects of science. Student FR from 2015-16 stated that "now my picture of science is that it can be affected by religion, by like society, where you live." Student HA from 2015-16 discussed the religious background of science: "Church was really involved in science in Galileo time and how the Church was really ruling science and deciding which theories were good and which weren't."

Also, most of participants confirmed the sociocultural aspects of science in different sub-categories. As an example of their responses, student FE from the 2016-17cohort provided his own explanation of the influence of society on science: "If you ask me if society influences science like Galileo time, I would say yes but nowadays it is not that obvious. So, you might say no but still, there are some influences of society but it is not that obvious and that's a thing I really didn't know before this class."

\subsubsection{Tentativeness}

Popper (1992) and Bromme \& Goldman (2014) consider that uncertainty and tentativeness are characteristic for empirical results. Ioannidis (2006) states that "Instead of solid knowledge, we should get used to the notion of tentative information". Understanding tentativeness also means to comprehend that findings may contradict each other or become obsolete when more reliable findings occur (Sinatra et al., 2014). 
The results of both studies demonstrated that participants in this course detected the tentative nature of scientific knowledge and students no longer see science as an absolute truth.

Four common themes were extracted from students' responses:

1) a new phenomenon could show up with the help of advanced technology, 2) changes in science could occur due to the inability of a scientific theory to explain new knowledge, 3) humans' ideas changes, 4) fundamental theories (such as Newton's laws in mechanics) will never change in their area of application. (extending the area of application as in special relativity and quantum mechanics could result in new theories)

In the interviews, students explained their ideas about how science progresses and what could possibly influence scientific progression.

As can be seen in Table 7 out of 6 students in 2015-16 and 6 out of 6 students in 2016-17 think that scientific knowledge is tentative.

As an example, Student JU from the 2015-16cohort brought an example from the Aristotelian and Galilean theories and explained the tentative nature of scientific knowledge:

"Relating it to the Aristotle/Galileo case, he had this theory that the earth was at the center of the universe and then here comes Galileo who says well no, the earth revolves around the sun."

From the 2016-17 cohort, student JO explained how human's scientific progress depend on the culture they live in: "depending on the culture we are in and what religion we have and other social factors. So, maybe what we believe here in North America is very different from I don't know ... like Asians maybe think different in that culture. So, how we approach stuff is going to be also different." Student SE discussed the tentative nature of science in terms of technology advancements and how it helps us to approach scientific phenomenon in a different way:

"we have new technology that allows us to be may be more precise and makes us realize that maybe: okay! Actually it's not right."

Data analysis showed that the majority of students from both years agreed that no scientific theory can ever be considered completely proven and they are always changing and evolving.

\subsubsection{Subjectivity}

Scientists do not conduct absolutely objective observations, do not reach objective conclusions and do not evaluate new evidence objectively (Lederman et al., 2002).

Just as students' interpretations of observed phenomena are influenced by their beliefs, values and previous knowledge, so too are those of scientists (Lederman, 2007).

Based on the interviews with participants in both years and as can be seen in Table 8 it was concluded that most of the students understand the subjectivity of science. 
Table 6. Common themes found in 2015-16 and 2016-17 participants.

\begin{tabular}{|c|c|c|c|}
\hline Yes/ NO & Sub-categories & $\begin{array}{c}2015-16 \text { cohort } \\
\text { (out of } 6 \text { interviewed students) }\end{array}$ & $\begin{array}{c}2016-17 \text { cohort } \\
\text { (out of } 6 \text { interviewed students) }\end{array}$ \\
\hline Yes & $\begin{array}{l}\text { The expectations of the culture } \\
\text { determine what to study; } \\
\text { scientists are motivated by social demands. }\end{array}$ & 2 & 2 \\
\hline Yes & $\begin{array}{l}\text { Scientists are members of society; } \\
\text { they are influenced by society } \\
\text { (education and ways of thinking) }\end{array}$ & 3 & 4 \\
\hline Yes & Religious background & 4 & 3 \\
\hline Yes & Gender and science & 3 & 2 \\
\hline No & Science is completely objective. & 1 & 2 \\
\hline
\end{tabular}

Table 7. Students' ideas about how science progresses. (common themes found in 2015-16 and 2016-17 participants).

\begin{tabular}{|c|c|c|c|}
\hline Change/ No change & Sub-categories & 2015 participants & 2016 participants \\
\hline Change & $\begin{array}{l}\text { a new phenomenon shows up with } \\
\text { the help of advanced technology }\end{array}$ & 4 & 3 \\
\hline Change & $\begin{array}{l}\text { the inability of a scientific theory } \\
\text { to explain new knowledge }\end{array}$ & 3 & 4 \\
\hline Change & humans' ideas change & 4 & 3 \\
\hline Change & No reason was provided & 2 & 1 \\
\hline No change & fundamental theories would be the same & 1 & 0 \\
\hline
\end{tabular}

Table 8. Subjectivity of science.

\begin{tabular}{|c|c|c|c|}
\hline Subjective/Objective & Sub-categories & 2015-16 participants & 2016-17 participants \\
\hline Subjective & $\begin{array}{l}\text { Science is influenced and driven by the } \\
\text { presently accepted scientific theories and } \\
\text { laws. The development of questions is also } \\
\text { based on current theory. }\end{array}$ & 4 & 3 \\
\hline Subjective & $\begin{array}{l}\text { Personal subjectivity is unavoidable. } \\
\text { (Personal preference) }\end{array}$ & 3 & 3 \\
\hline Objective & Science is completely objective. & 1 & 2 \\
\hline
\end{tabular}

Two common sub-categories were extracted from students' responses:

1) Science is influenced and driven by the presently accepted scientific theories and laws. The development of questions is also based on current theory, 2) Personal subjectivity is unavoidable in scientific process.

In seeking to account for subjectivity of science, 5 out of 6 students in 2015-16 and 4 students out of 6 in 2016-17 felt that science is dependent on scientists' background, their levels of education and their personal preferences as well as exterior influences such as currently accepted theories. Students thought that observations are not completely objective and can be affected by related scientific theory. They explained that scientists always learn basic knowledge and then they try to build upon it, which can make science subjective. Student HA dis- 
cussed an example on how presently accepted theory influences science: "Most of the students choose their major and then in their masters and $\mathrm{PhD}$, they are working on one of the accepted theories and they don't cross link with the other ones." Student GA from the 2015-16 cohort also mentioned the exterior biases in scientific knowledge: "you're shaped by the knowledge we're already aware of. You'll think 'maybe this mechanism is like that mechanism'. You won't be able to come up with completely off-the-wall theory." Student MA from the 2016-17cohort explained how scientists' personal biases make science subjective: "Well, I think we are all humans and we all have like biases and so even with our own research, we can't be completely objective and so where Aristotle was arguing about his research and he didn't want to see the other facts or the other discoveries that were happening at the same time. I think that if you've been working on a project or on a theory for like 20 years, I think it can be hard to ... like if someone comes up with a different idea or something that rejects your theory, I think it can be hard to switching and be like: okay! I was wrong because you've been putting and investing project. So, I think just so much energy, time and money for that project. So, I think just personal biases and social factors still have influences as much as it did in those days."

\section{Overview}

This course was taught using student-centered instruction. We measured the effects of this course on students understanding about the NOS. It would seem that there were impressive changes in students' understanding of the NOS. More specifically, there were changes in students' views about the evolution of theory. Hence, we conclude that using different methods of student-centered instruction (section 3) is effective in teaching the NOS to science students.

Generally, students agreed science is continuously changing due to using advanced technologies. Students accepted the tentative nature of science and had a strong view that scientific knowledge progresses. Some other students felt that scientific knowledge does not change. For those students, theories such as Newton's gravitation law do not drastically change but are refined to be more accurate.

Second, on the topic of subjectivity of science, the students felt that science is influenced and driven by the presently accepted scientific theories and laws and personal subjectivity is unavoidable. In particular, when data were not solid enough, students felt scientists filled in gaps from their own assumptions and imagination. Students from both the 2015-16 and the 2016-17 cohorts showed considerable change in each sub-category of subjectivity of science. For example, 4 students out of 6 in 2016-17 and 5 students out of 7 in 2015-16 showed progress in the first sub-category (science is influenced by currently accepted theory in scientific society) of the subjectivity of science (second theme).

Third, the majority of the participants agreed there was mutual interaction between science and society. Some students thought politics and religion have resulted in abuse of scientists and science for example Galileo and Darwin. They 
also discussed the influence of society on scientists as members of society; Participants of both years were showed a good understanding of the socio-cultural aspects of science.

This section will discuss the ways the student-centered teaching improved the students' understanding of NOS during two semesters by comparing the cases.

Reflective Writing products also show that in the beginning, students saw science as very straightforward and set in stone. In general, student writings became clearer and more understandable by the end of semester. Moreover, students' understanding of science changed.

The overall results showed that the student-centered classroom helped the students to improve their understanding of the NOS. This study should be helpful for science educators in designing their science courses for first year science students. Also, this study gives instructors information about how students can go through conceptual change and become an active learner.

\section{Conclusion}

Too few science programs require any coursework involving a deep and robust understanding of the NOS (Backhus \& Thompson, 2006). Many articles in the journal Science \& Education consider contributions to teaching and learning about the NOS. However, in the majority of these studies, the authors' claims about adequately and deliberately teaching and learning about the NOS to science students are not backed up by data to help us know specifically what educational methods actually help learning, or, if it does help, how it helps and what we need to do to make it an effective learning activity.

Answers to such questions are helpful for both educators, in terms of guiding future students, as well as researchers, who seek a deeper understanding of the processes involved in implementing such activities. In this study, we conducted interviews and combined the qualitative analysis of the interviews, student writing products and classroom observational data following a qualitative research approach, as recommended by Corbin \& Strauss (2015) and Packer (2010) to examine these research questions. We also studied students' understanding of science to explore whether student-centered teaching is helpful to achieve effective NOS learning outcomes.

This paper establishes three main items:

1) The characteristics of student-centered teaching and educational methods that can be used to help students accommodate the course material.

2) Participants' improvement in understanding specific aspects of the Nature of Science.

3) Improvements and changes in students' philosophical attitudes towards Nature of Science.

\section{Conflicts of Interest}

The authors declare no conflicts of interest regarding the publication of this paper. 


\section{References}

Abd-El-Khalick, F., \& Lederman, N. G. (2000). Improving Science Teachers' Conceptions of Nature of Science: A Critical Review of the Literature. International Journal of Science Education, 22, 665-701. https://doi.org/10.1080/09500690050044044

Aikenhead, G. S. (1987). High-School Graduates' Beliefs about Science-Technology-Society. III. Characteristics and Limitations of Scientific Knowledge. Science Education, 71, 459-487. https://doi.org/10.1002/sce.3730710402

Akcay, B., \& Akcay, H. (2015). Effectiveness of Science-Technology-Society (STS) Instruction on Student Understanding of the Nature of Science and Attitudes toward Science. International Journal of Education in Mathematics, Science and Technology, 3, 37-45. https://doi.org/10.18404/ijemst.50889

American Association for the Advancement of Science (AAAS) (1990). Science for All Americans. New York: Oxford University Press.

Backhus, D. A., \& Thompson, K. W. (2006). Addressing the Nature of Science in Preservice Science Teacher Preparation Programs: Science Educator Perceptions. Journal of Science Teacher Education, 17, 65-81.

Bacon, F. (1863) The New Organon, in The Works (Vol. 8). Translated by of James Spedding.

Bransford, J. D., Zech, L., Schwartz, D., Barron, B., Vye, N., \& CTGV. (1999). Designs for Environments that Invite and Sustain Mathematical Thinking. In Cobb, P. (Ed.), Symbolizing, Communicating, and Mathematizing: Perspectives on Discourse, Tools, and Instructional Design (pp. 275-324). Mahwah, NJ: Lawrence Erlbaum Associates.

Bromme, R., \& Goldman, S. R. (2014). The Public's Bounded Understanding of Science. Educational Psychology, 49, 59-69. https://doi.org/10.1080/00461520.2014.921572

Cakici, Y., \& Bayir, E. (2012). Developing Children's Views of the Nature of Science through Role Play. International Journal of Science Education, 34, 1075-1091. https://doi.org/10.1080/09500693.2011.647109

Carnes, M. C. (2014). Minds on Fire: How Role-Immersion Games Transform College. Boston, MA: Harvard University Press. https://doi.org/10.4159/harvard.9780674735606

Clough, M. P., \& Olson, J. K. (2008). Teaching and Assessing the Nature of Science: An Introduction. Science \& Education, 17, 143-145.

Connally, P., \& Vilardi, T. (1989). Writing to Learn Mathematics and Science, Teachers. New York: College Press.

Corbin, J., \& Strauss, A. L. (2015). Basics of Qualitative Research (4th Ed.) Thousand Oaks, CA: Sage Publishing.

Cornelius-White, J. (2007). Learner-Centered Teacher-Student Relationships Are Effective: A Meta-Analysis. Review of Educational Research, 77, 113-143. https://doi.org/10.3102/003465430298563

Creswell, J. W., Hanson, W. E., Clark Plano, V. L., \& Morales, A. (2007). Qualitative Research Designs: Selection and Implementation. The Counseling Psychologist, 35, 236-264. https://doi.org/10.1177/0011000006287390

de Carvalho, A. M. P., \& Vannucchi, A. I. (2000). History, Philosophy and Science Teaching: Some Answers to "How?". Science \& Education, 9, 427-448. https://doi.org/10.1023/A:1008709929524

Denzin, N. K. (1978). Triangulation: A Case for Methodological Evaluation and Combination. Sociological Methods, 339-357.

Duschl, R. (2000). Making the Nature of Science Explicit. Improving Science Education: 
The Contribution of Research (pp. 187-206).

Erstad, O., \& Sefton-Green, J. (2012). Identity, Community, and Learning Lives in the Digital Age. Cambridge \& New York: Cambridge University Press. https://doi.org/10.1017/CBO9781139026239

Fullan, M. G. (1991). The New Meaning of Educational Change (pp. 30-46). New York: Teachers College Press.

Gadamer, H. G. (1975/2004). Truth and Method. New York: Continuum International Publishing Group.

Galili, I., \& Hazan, A. (2000). Learners' Knowledge in Optics: Interpretation, Structure and Analysis. International Journal of Science Education, 22, 57-88. https://doi.org/10.1080/095006900290000

Greene, J. C., Caracelli, V. J., \& Graham, W. F. (1989). Toward a Conceptual Framework for Mixed-Method Evaluation Designs. Educational Evaluation and Policy Analysis, 11, 255-274. https://doi.org/10.3102/01623737011003255

Huang, X., \& Kalman, C. S. (2012). A Case Study on Reflective Writing. Journal of College Science Teaching, 42, 92-99.

Ioannidis, J. P. A. (2006). Concentration of the Most-Cited Papers in the Scientific Literature: Analysis of Journal Ecosystems. PLoS ONE, 1, e5.

Kalman, C. S. (2002). Developing Critical Thinking in Undergraduate Courses: A Philosophical Approach. Science \& Education, 11, 83-94. https://doi.org/10.1023/A:1013071130538

Kalman, C. S. (2010). Enabling Students to Develop a Scientific Mindset. Science \& Education, 19, 147-163. https://doi.org/10.1007/s11191-009-9186-6

Kalman, C. S. (2011). Enhancing Students' Conceptual Understanding by Engaging Science Text with Reflective Writing as a Hermeneutical Circle. Science \& Education, 20, 159-172. https://doi.org/10.1007/s11191-010-9298-Z

Kalman, C. S. (2018). Successful Science and Engineering Teaching: Theoretical and Learning Perspectives (2nd ed.). Dordrecht: Springer.

https://doi.org/10.1007/978-3-319-66140-7

Kalman, C. S., Aulls, M. W., Rohar, S., \& Godley, J. (2008). Students' Perceptions of Reflective Writing as a Tool for Exploring an Introductory Textbook. Journal of College Science Teaching, 37, 74.

Kennedy, M. M., \& Barnes, H. (1994). Implications of Cognitive Science for Teacher Education. In J. N. Mangieri, \& C. C. Block (Eds.), Creating Powerful Thinking in Teachers and Students: Diverse Perspectives (pp. 195-212). New York: Holt Rinehart and Winston.

Khanam, W. N. (2014). Helping Students to Get a Better Understanding of Physics Concepts Using the Learning Tool "Course Dossier Method”. Diss. Concordia University.

Khanam, W. N., \& Kalman, C. S. (2017). Implementation and Evaluation of the Course Dossier Methodology. Canadian Journal for the Scholarship of Teaching and Learning, 8, Article 7. http://ir.lib.uwo.ca/cjsotl_rcacea/vol8/iss1/7 https://doi.org/10.5206/cjsotl-rcacea.2017.1.7

Kuhn, T. S. (1963). The Structure of Scientific Revolutions. Chicago, IL: University of Chicago Press.

Lederman, N. G. (1992). Students' and Teachers' Conceptions of the Nature of Science: A Review of the Research. Journal of Research in Science Teaching, 29, 331-359.

https://doi.org/10.1002/tea.3660290404 
Lederman, N. G. (2007). Nature of Science: Past, Present, and Future. In S. K. Abell, \& N. G. Lederman (Eds.), Handbook of Research on Science Education (pp. 831-879). Mahwah, NJ: Lawrence Erlbaum Associates.

Lederman, N. G., Abd-El-Khalick, F., Bell, R. L., \& Schwartz, R. S. (2002). Views of Nature of Science Questionnaire: Toward Valid and Meaningful Assessment of Learners' Conceptions of Nature of Science. Journal of Research in Science Teaching, 39, 497-521. https://doi.org/10.1002/tea.10034

Lincoln, Y. S., \& Guba, E. G. (1985). Naturalistic Inquiry. Thousand Oaks, CA: Sage Publishing.

Littleton, K., \& Mercer, N. (2013). Interthinking: Putting Talk to Work. London: Routledge.

Merriam, S. B. (1998). Qualitative Research and Case Study Applications in Education. Revised and Expanded from Case Study Research in Education. San Francisco, CA: Jossey-Bass Publishers.

Millar, R., \& Osborne, J. F. (1998). Beyond 2000: Science Education for the Future: The Report of a Seminar Series Funded by the Nuffield Foundation. London: King's College London, School of Education.

Minnaert, A., Boekaerts, M., \& de Brabander, C. (2007) Autonomy, Competence, and Social Relatedness in Task Interest within Project-Based Education. Psychological Reports, 101, 574-586. https://doi.org/10.2466/pr0.101.2.574-586

Müller, F. H., \& Louw, J. (2004). Learning Environment, Motivation and Interest: Perspectives on Self-Determination Theory. South African Journal of Psychology, 34, 169-190. https://doi.org/10.1177/008124630403400201

National Science Board (US). (2002). Science \& Engineering Indicators. National Science Board.

Osborne, J., Simon, S., \& Collins, S. (2003). Science \& Engineering Indicators: Attitudes towards Science: A Review of the Literature and Its Implications. International Journal of Science Education, 25, 1049-1079. https://doi.org/10.1080/0950069032000032199

Packer, S. (2010). Statistics Prepared for Commonwealth Research on Education in Small States. UK: University of Bristol.

Parkinson, J. (2004). Improving Secondary Science Teaching. London: Routledge Falmer. https://doi.org/10.4324/9780203464328

Patton, M. Q. (1999). Enhancing the Quality and Credibility of Qualitative Analysis. Health Services Research, 34, 1189-1208.

Popper, K. R. (1992). The Logic of Scientific Discovery. London: Routledge.

Porter, S. E., \& Robinson, J. C. (2011). Hermeneutics: An Introduction to Interpretive Theory. Grand Rapids, MI: Eerdmans.

Priest, H., Roberts, P., \& Woods, L. (2002). An Overview of Three Different Approaches to the Interpretation of Qualitative Data. Part 1: Theoretical Issues. Nurse Researcher, $10,43$.

Rudge, D. W., \& Howe, E. M. (2009). An Explicit and Reflective Approach to the Use of History to Promote Understanding of the Nature of Science. Science \& Education, 18, 561-580. https://doi.org/10.1007/s11191-007-9088-4

Sinatra, G. M., Kienhues, D., \& Hofer, B. K. (2014). Addressing Challenges to Public Understanding of Science: Epistemic Cognition, Motivated Reasoning, and Conceptual Change. Educational Psychologist, 49, 123-138.

https://doi.org/10.1080/00461520.2014.916216 
Smit, K., de Brabander, C. J., \& Martens, R. L. (2014). Student-Centred and Teacher-Centred Learning Environment in Pre-Vocational Secondary Education: Psychological Needs, and Motivation. Scandinavian Journal of Educational Research, 58, 695-712. https://doi.org/10.1080/00313831.2013.821090

Supovitz, J. A., \& Turner, H. M. (2000). The Effects of Professional Development on Science Teaching Practices and Classroom Culture. Journal of Research in Science Teaching, 37, 963-980.

https://doi.org/10.1002/1098-2736(200011)37:9<963::AID-TEA6>3.0.CO;2-0

Trochim, W. M. K. (1989). Outcome Pattern Matching and Program Theory. Evaluation and Program Planning, 12, 355-366. https://doi.org/10.1016/0149-7189(89)90052-9

Vygotsky, L. S. (1978). Mind in Society: The Development of Higher Psychological Processes. Cambridge, MA: Harvard University Press.

Wahbeh, N., \& Abd-El-Khalick, F. (2014). Revisiting the Translation of Nature of Science Understandings into Instructional Practice: Teachers' Nature of Science Pedagogical Content Knowledge. International Journal of Science Education, 36, 425-466. https://doi.org/10.1080/09500693.2013.786852

Wink, J., \& Putney, L. (2002). A Vision of Vygotsky (pp. 60-63). Boston, MA: Allyn \& Bacon.

Yin, R. K. (2018). Case Study Research Design and Methods (6th Ed.). Thousand Oaks, CA: Sage Publishing. 